\title{
A QGIS PLUGIN FOR THE SEISMIC VULNERABILITY ASSESSMENT OF URBAN CENTERS: APPLICATION TO THE CITY OF POPOLI IN ABRUZZO (ITALY)
}

\author{
A. GONZALEZ ${ }^{1}$, A. BASAGLIA ${ }^{1}$, E. SPACONE ${ }^{1}$ AND G. BRANDO ${ }^{1^{*}}$ \\ ${ }^{1}$ Department of Engineering and Geology \\ University “G. D’Annunzio" Chieti-Pescara \\ Viale Pindaro 42, 65127 Pescara, Italy \\ email: giuseppe.brando@unich.it (*corresponding author)
}

Keywords: Seismic vulnerability assessment, Seismic Maps, GIS

\begin{abstract}
Seismic vulnerability assessment of buildings is a process of paramount importance for identifying those areas in a city demanding higher attention with respect to potential earthquake attacks. Methods for evaluating seismic vulnerability require a more or less accurate survey of the buildings geometrical and mechanical features, as well as of the structural systems, in order to identify the vulnerability classes to which they belong. However, even for relatively small-sized cities, the task of deriving vulnerability maps may be truly time consuming. Therefore, the development of automatic tools for mapping vulnerabilities of urban areas is necessary to reduce this effort significantly.

QGIS (www.qgis.org) is a free open source software which includes a large number of peculiar packages, that make it a powerful tool and that can be well integrated or adapted with new components or plugins. In this paper, a plugin for assisting in the generation of vulnerability maps of an urban area is shown. The presented QGIS tool is applied to a case study, the historic city centre of Popoli, in the Abruzzi region (Central Italy), which belongs to a relevant earthquake-prone area and that was affected by two major seismic sequences in 2009 and in 2016-2017. Potential damage scenarios are presented and discussed, deriving useful information that could be applied in risk mitigation strategies.
\end{abstract}

\section{INTRODUCTION}

The evaluation of seismic risk at the urban scale, as well as its visualization on maps, is a theme of crucial interest for public stakeholders and private entities, such as insurance or reinsurance companies. Seismic risk, $R$, includes the potential physical, economic, social and environmental losses due to the earthquake hazard that may occur in a specified region, given the vulnerability of its built environment, and within a defined period of time. A commonly used definition of the seismic risk is the convolution of hazard $(H)$, exposure $(E)$, and vulnerability $(V)$, as symbolically expressed by Eq. 1 [1]:

$$
R=H \otimes E \otimes V
$$

Seismic hazard is the "potentially damaging effects of earthquake at a particular location". 
These effects are related to the surface rupture or induced ground shaking.

Exposure is related to the socio-economic value of the built environment in the area under assessment. It includes the buildings occupants, the replacement costs (repair or reconstruction), the turnover of commercial and industrial facilities, and other aspects.

Vulnerability is related to the quality of the built environment and can be defined as "the degree of damage that is expected under a specified level of seismic demand" [2].

The seismic vulnerability of a building is usually evaluated through finite-element (FEM) analyses, which allow to accurately model the structure and its response under different ground shakings. However, when the evaluation moves to the urban scale and several constructions are considered, the use of more rapid approaches is preferable. Among rapid approaches, those based on the evaluation of vulnerability indices or based on the adoption of fragility curves, after the reconnaissance of few structural features, found a large consensus in the last years $[3,4,5]$. These studies often represent scenarios on geo-referenced maps, to make easier to communicate risk to Stakeholders and the population.

In the light of this premise, this paper presents a tool implementing different vulnerability models to be applied at the urban scale, as well as their outcomes through maps. The tool is implemented in a QGIS environment (www.qgis.org) and applied to a case study, the city centre of Popoli, Abruzzi Region, Italy. In order to prove the versatility of the tool, two types of predictive model are used: a vulnerability index-based method for old masonry buildings, that represent a specific vulnerability class, and fragility curves retrieved by literature for other types

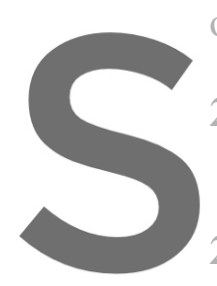
of buildings.

2.

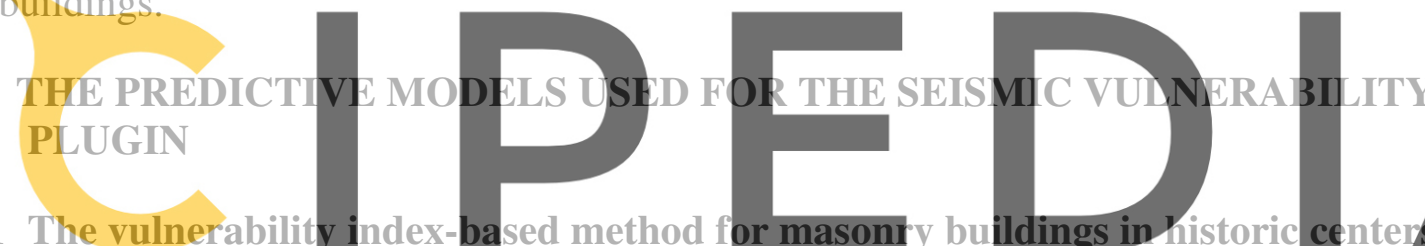

2.1. The vulnerability index-based method for masoni

touldings in historic centers

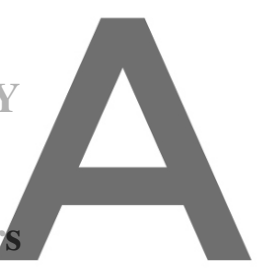

In recent years, a predictive model for the seismic vulnerability assessment of historic

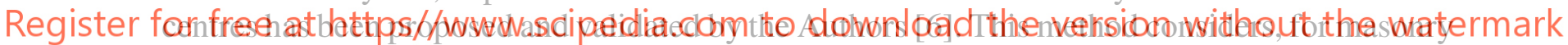
buildings, a vulnerability index $i_{v}$, resulting from a weighted sum of 14 vulnerability parameters, $P_{k}$, assigned downstream of an accurate geometrical and structural survey carried out on all the buildings -or on a statistically representative stock- that form the centre. Given the average value of all the vulnerability indices, $i_{v}^{*}$, this is used in order to assess the mean damage grade $\mu_{D}$ expected for the whole historic centre under a specific earthquake intensity, $I$ (MKS scale), according to the formulation given by Sandi and Floricel [7]. The damage grade $\mu_{D}$ is therefore used for applying the binomial distribution reported in Eq. (2) in order to assess the probability $p_{k}$ of attaining one of the six damage grades $k$-expressed by integers ranging between 0 (no damage) and 5 (full collapse)- according to the classification proposed for the European Macroseismic Scale, EMS-98 [8].

$$
p_{k}=\frac{5 !}{k !(5-k) !} \cdot\left(\frac{\mu_{D}}{5}\right)^{k} \cdot\left(1-\frac{\mu_{D}}{5}\right)^{5-k}
$$




\subsection{The fragility curves dataset-based method for RC buildings outside of the historic centre}

Fragility curves relates the probability of a building to reach or exceed a certain level of damage, $P(D k)$, for increasing earthquake intensities [9], see Figure 1 [10]. Fragility curves are derived through non-linear static or dynamic analyses of structures. Levels of damage are defined by fixing thresholds or Engineering-Demand Parameters (EDP), such as the inter-storey drift. Different earthquake intensity measures (IMs) can be used to quantify the level of shaking. The peak ground acceleration (PGA) is commonly used in Europe, while the pseudospectral acceleration (PSA) is commonly used in the United States.

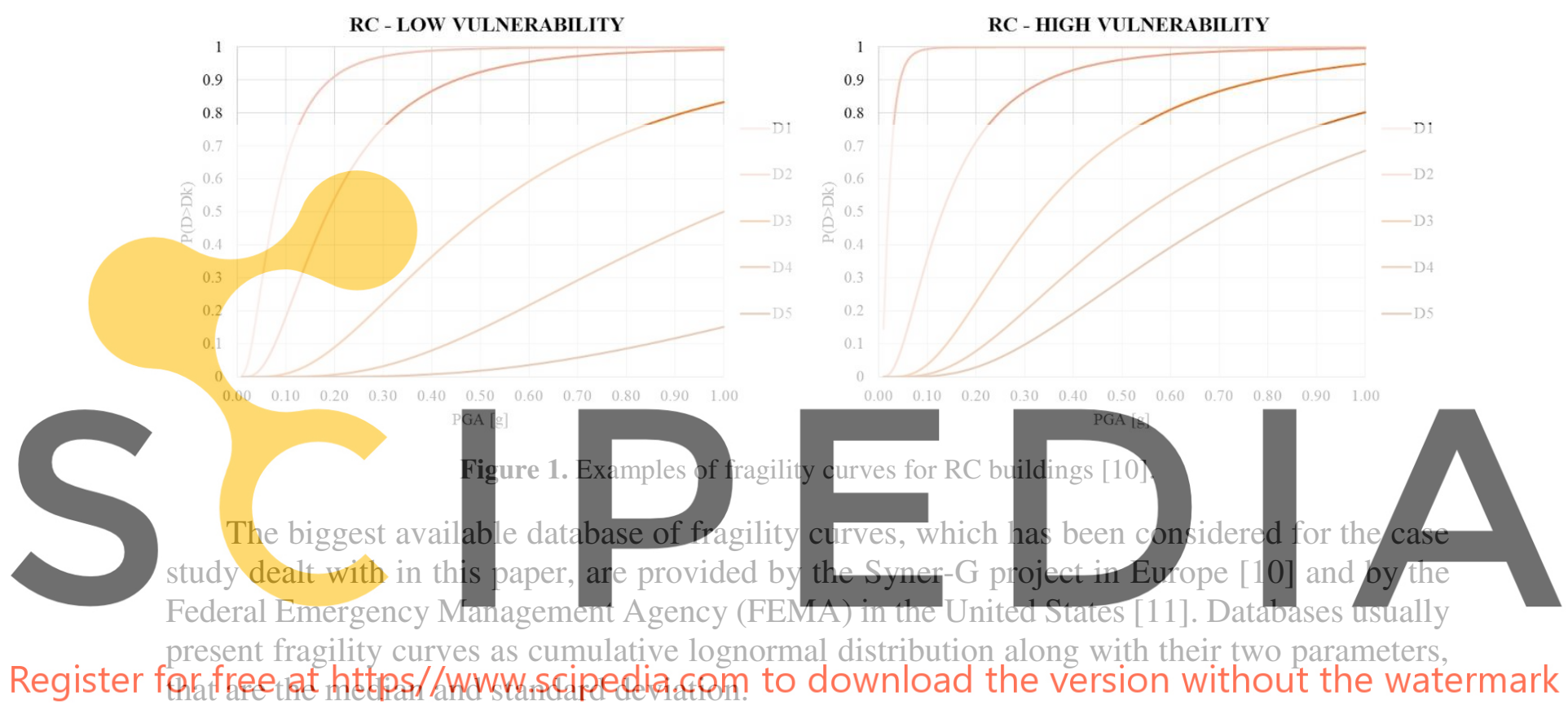

\section{DECRIPTION OF THE SEISMIC VULNERABILITY PLUGIN}

\subsection{General description}

Quantum GIS or QGIS (www.qgis.org) is a free open source Geographical Information System (GIS) software that includes particular packages that make it a powerful tool. QGIS is currently used by a wide and international community and is constantly updated [12]. The User interacts with the software via a Graphical User Interface (GUI), which contains an integrated set of menus, toolbars and other options. The GUI gives access to the GIS tools, while the toolset defines the capabilities or function of the GIS for processing geographic data.

The inclusion of the plugin function to the interface QGIS is shown in

Figure 2. It adds a seismic risk calculator to the QGIS environment and supports the User with new integrated functionalities related to the automated application of adopted vulnerability models.

Once that a shapefile (.shp) that holds the geometry and attribute information (identification, address, description, etc.) of all the buildings under assessment is uploaded, so 
that a geographical database is generated into the GIS environment, the functionalities, whose development is described in the following paragraphs, have to be implemented. For a better comprehension, the map referred to the studied urban centre of Popoli is shown.
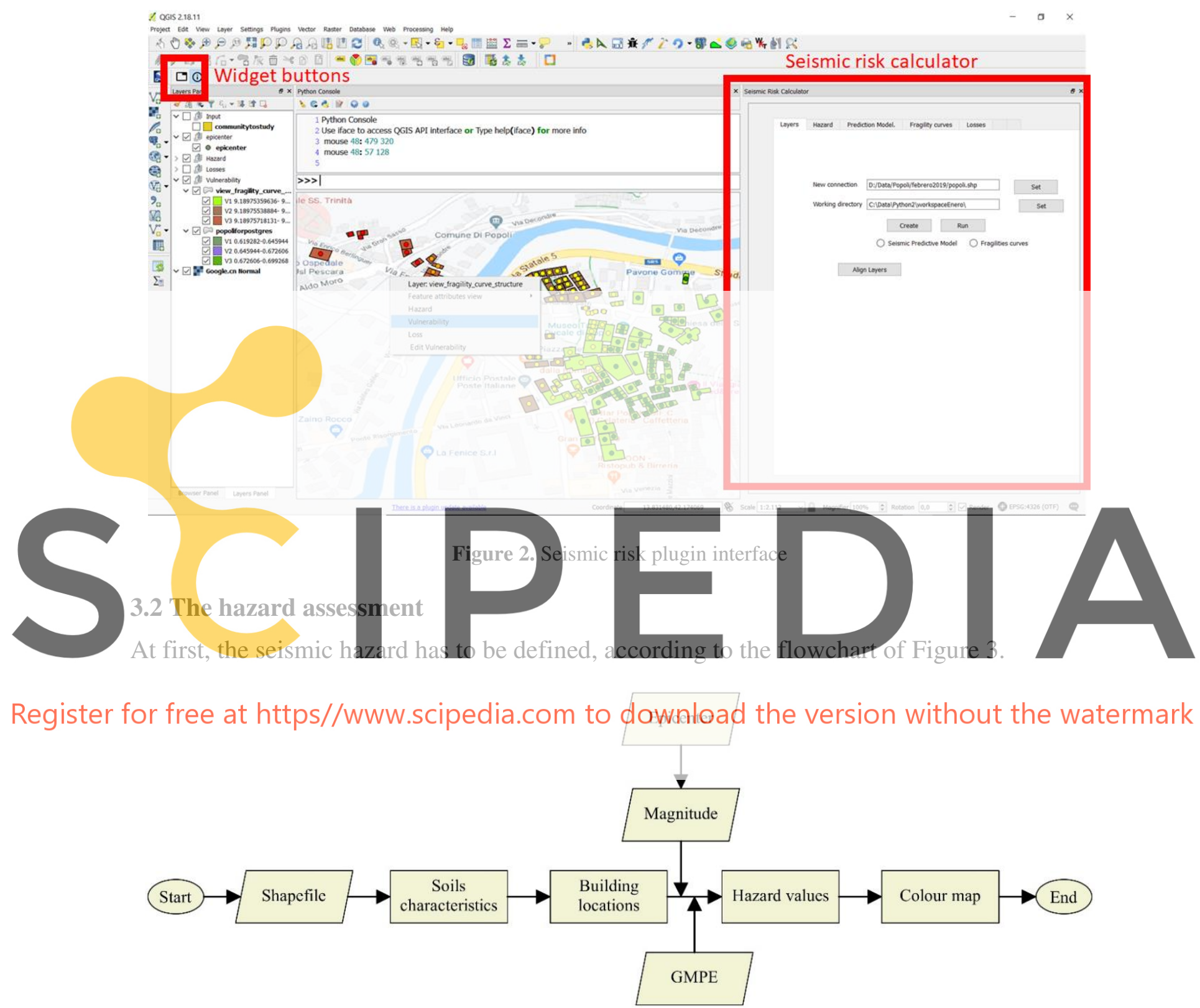

Figure 3. Seismic hazard analysis with the proposed QGIS tool.

The tool gives an estimation of the hazard values, taking in consideration Ground Motion Prediction Equations (GMPEs) [13] or attenuation laws. These equations return the level of ground shaking at any given location, considering the possible amplification phenomena due to the soil characteristics and the attenuation due to the distance. In particular, the general form of the equation Eq.3 used for regression analysis [14] is implemented 
$\log (\mathrm{PSA})=\mathrm{a}+\mathrm{bM}+\mathrm{cR}+\mathrm{dS}$

where, PSA is the geometric mean of two horizontal spectral accelerations at various periods; $M$ [15] is moment magnitude, $\mathrm{R}$ is hypocentral distance in $\mathrm{km}, \mathrm{S}$ is a site factor ( 0 for rock sites and 1 for soil sites) and $\mathrm{a}, \mathrm{b}, \mathrm{c}$ and $\mathrm{d}$ are constants to be determined from regression analysis.

Having defined all inputs, the tool is able to calculate the ground acceleration corresponding to the site of each all building, as reported in Figure 4.

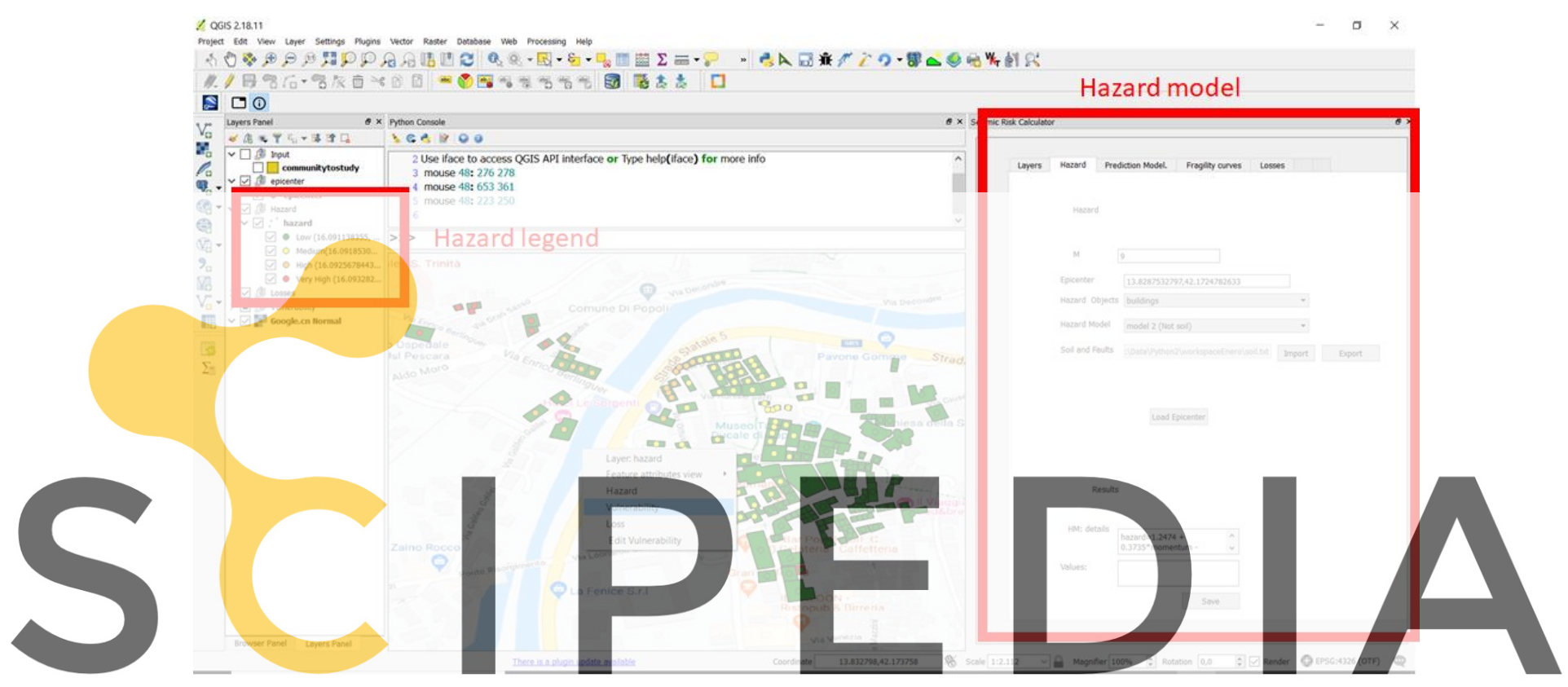

Figure 4. Calculated hazard for a community of study (shapefile).

Register for free at https//www.scipedia.com to download the version without the watermark

\subsection{Vulnerability evaluation}

As stated before, two methods for the vulnerability evaluation have been considered: a method based on the definition of a vulnerability index, reliable for masonry buildings belonging to historic centres, and the other based on the application of fragility curves, for the other building types (Fig. 5). Obviously, the methods cannot be applied simultaneously, thus a preliminary step consists in dividing the urban centre in homogeneous compound, where most of the building present the same features, and to merge at the end the obtained maps, such as the one shown in Figure 6.

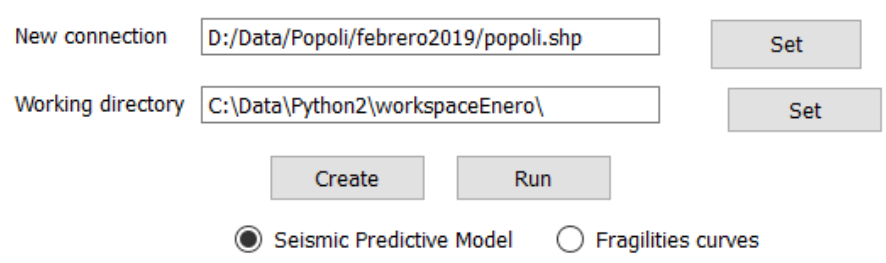

Figure 5. Selection of the method to apply in the seismc vulnerabilty evaluation. 
With reference only to the masonry building of the historic centre, after a structural and geometrical survey of all examined buildings, the vulnerability parameters, $P_{k}$, have been assigned so that the vulnerability index, $i_{v}$, has been evaluated and mapped, see Figure 6.

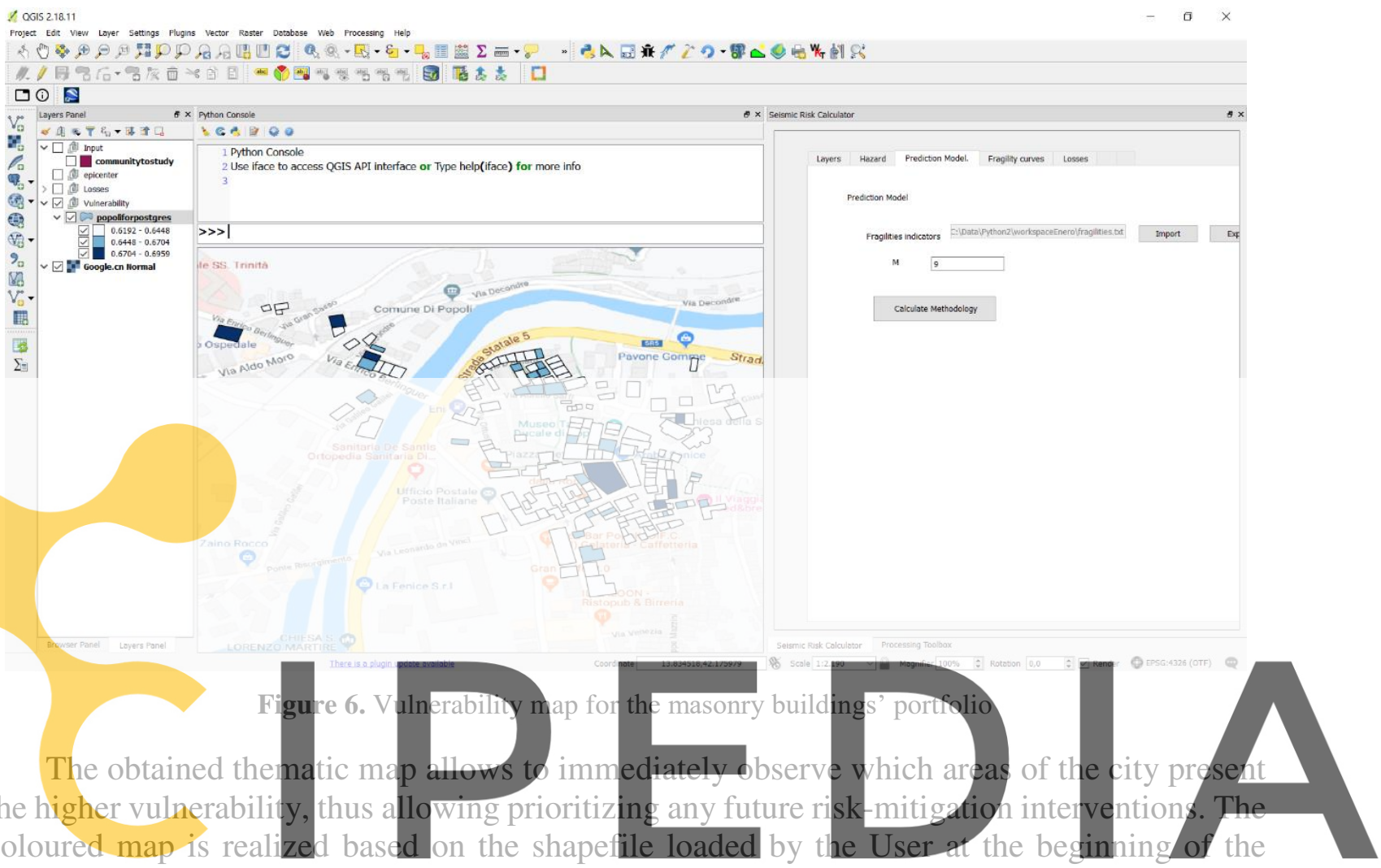

analysis. The user can update any of the vulnerability parameters in one Excel file and

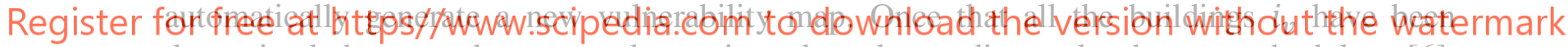
determined, the mean damage grade, $\mu_{D}$, is evaluated according to the chosen methodology [6].

The evaluation and mapping of the vulnerability and damage is shown in the flow diagram of Figure 7.

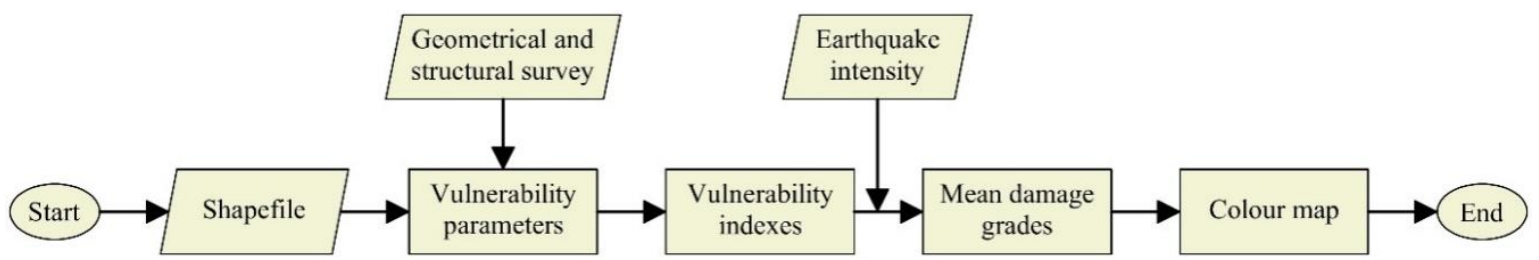

Figure 7 . Calculation and mapping of the vulnerability index and mean damage grade using a predictive model.

Then, RC buildings outside the historical centre are divided into topological classes after a visual structural and geometrical inspection. Each class represents all buildings whose response towards a seismic event is deemed comparable. Usually, similarities in terms of construction material, construction period, number of floor and irregularities in plan and in height are considered in the class definition. Subsequently, a set of fragility curves is assigned to each class [10], and are uploaded in the tool. In this way, given an earthquakes of defined intensity, 
the fragility curves will return the expected damage probabilities, $P(D k)$. The process is shown in the flow diagram of Figure 8.

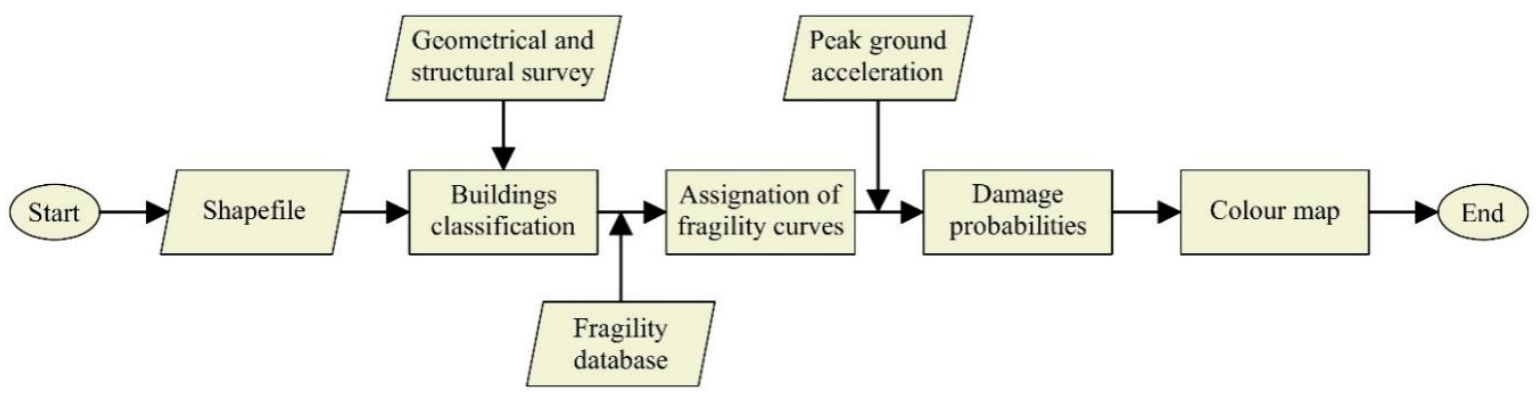

Figure 8. Calculation and mapping of the damage probabilities using fragility curves.

\subsection{Exposure definition for loss assessments}

In seismic risk assessments, losses are usually considered in terms of expected fatalities, injuries, and repair/replacement costs. In order to include the losses in the proposed tool, the building repair/replacement cost per square meter has to be assigned. The repair/replacement cost is defined as the required monetary value to construct a building with the same characteristics according to the current costs [16]. In case this information is not available, average values may be used. For example, average values of repair/replacement costs for reconstruction after the

Moreover, building in the tool by filling a w

Once the hazard is
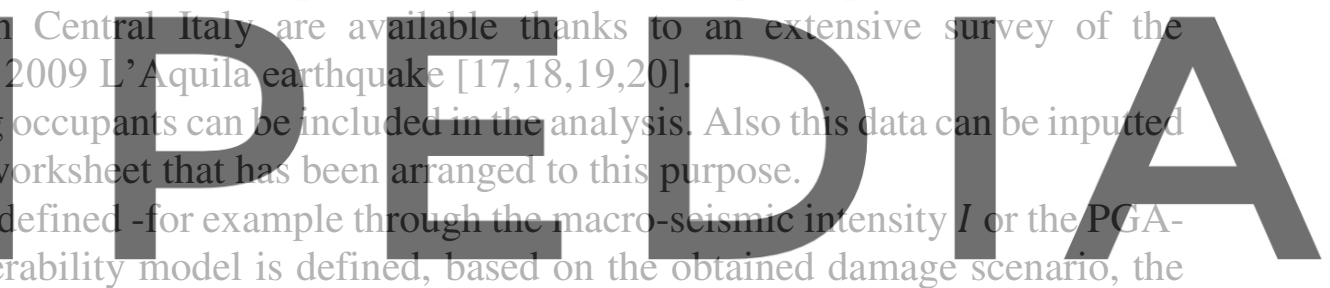

and once that the vulnerability model is defined, based on the obtained damage scenafio, the expected number of casualties and repair/replacement costs can be evaluated. Loss estimations

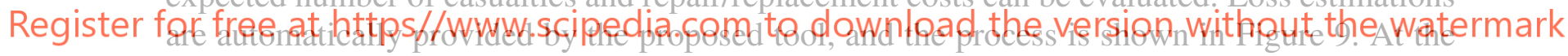
current stage, the casualty estimation is performed using the approach proposed by Zuccaro and Cacace (2011) [20] that can be applied with both the Vuinerability Index method and the fragility curves.

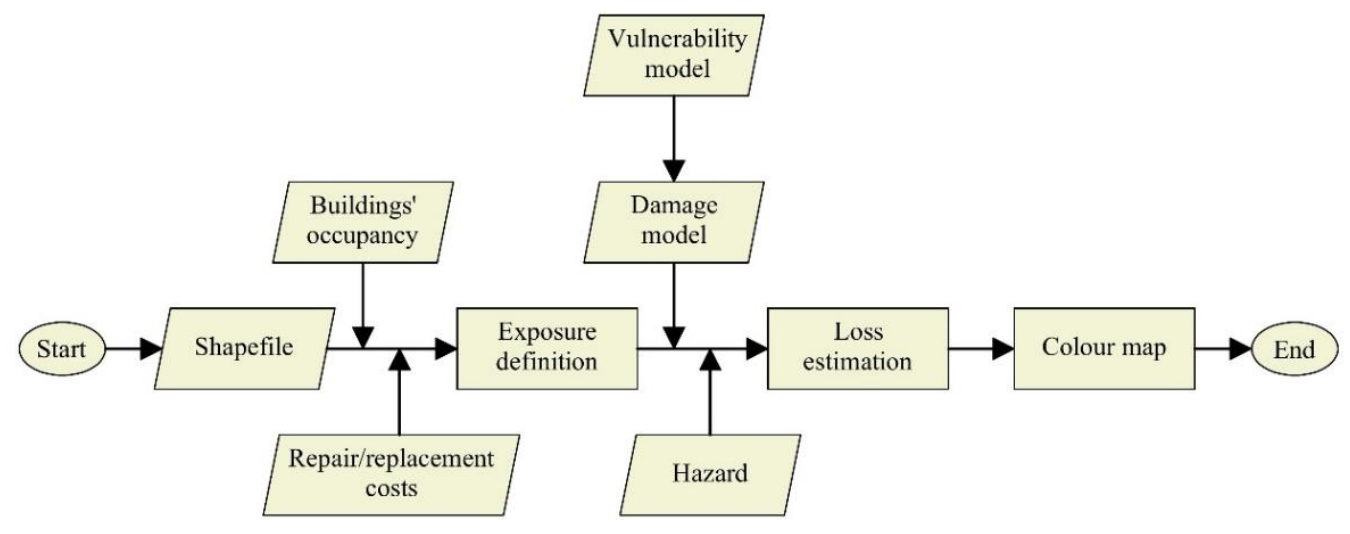

Figure 9. Calculation of socio-economic losses. 


\subsection{Visualization of results}

Once that the necessary data are loaded and once that the different kind of analysis are performed, the User can query the outcomes of the evaluation in an interactive way, as it is shown in Figure 10. It is possible to click on one of the buildings and the tool will show the detail of both the input and the output data used of the analysis. For doing this, the "Inspect data button" has to be activated.

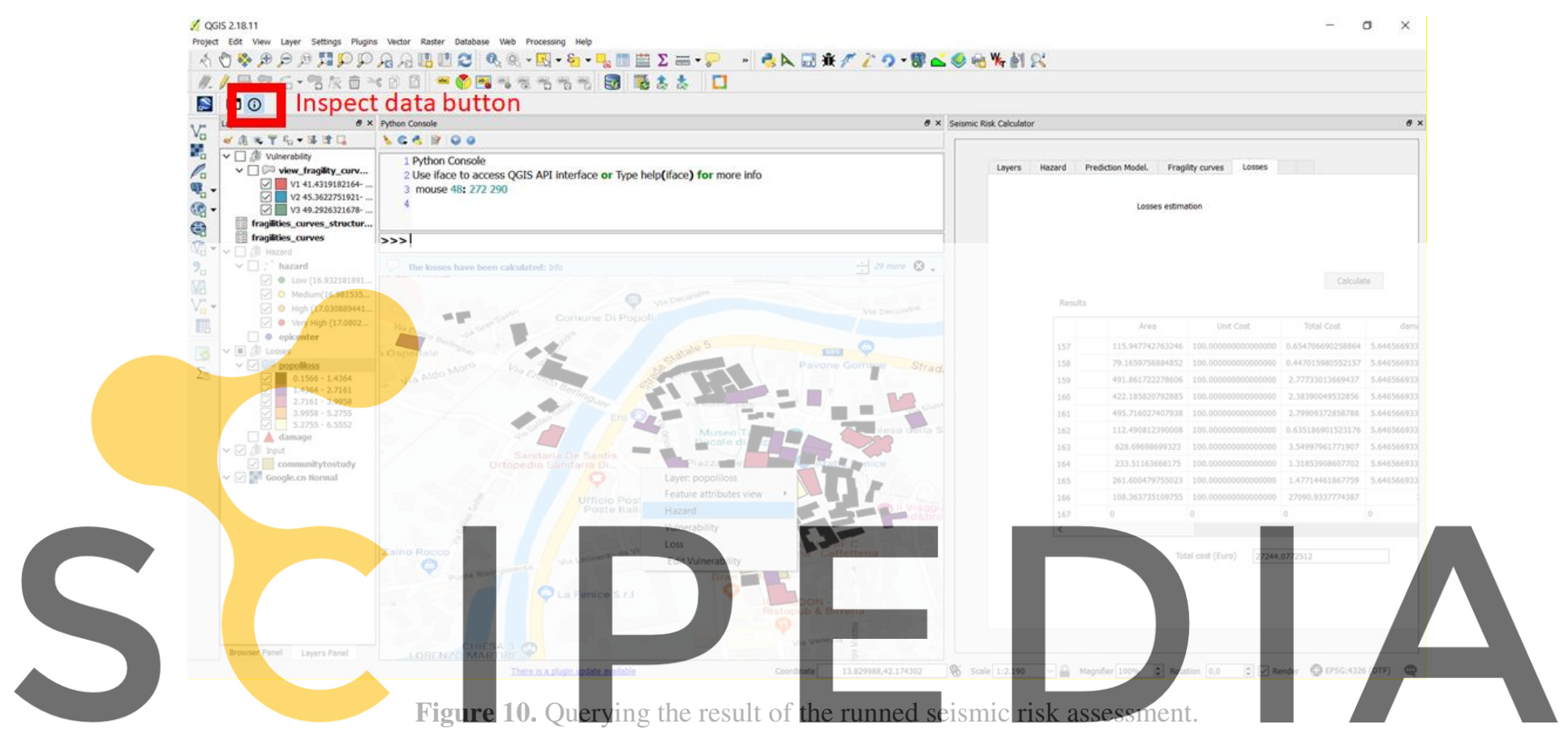

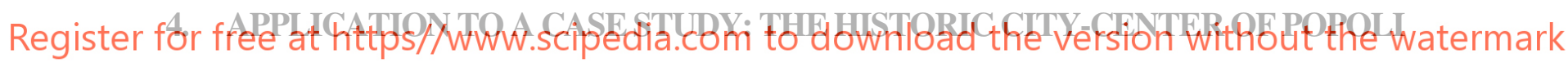

Popoli is a small town of approximately 5000 people in the Abruzzi Region, Central Italy, see Figure 11.

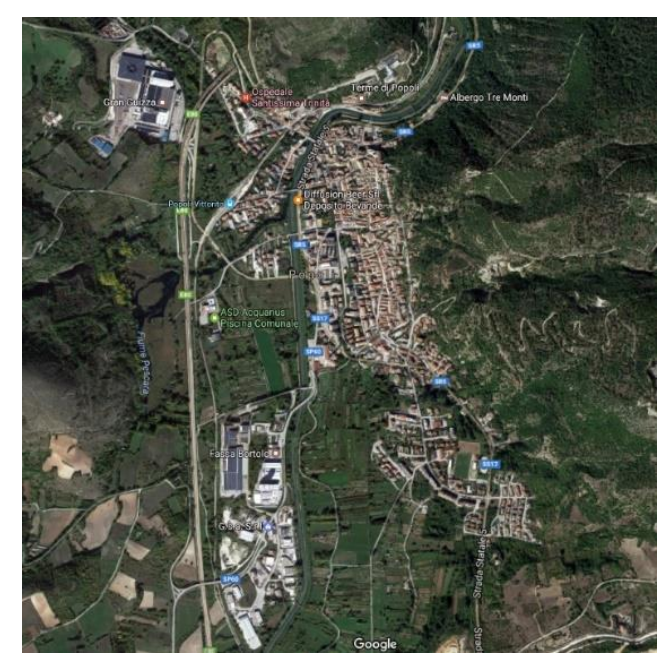

Figure 11. Popoli aerial view. 
The area has been affected by two major seismic sequences in 2009 [22] and in 2016-2017 [23]. The city has been selected as a case study because, despite its small size, it has a public hospital, a K-12 school system, two major industrial areas, two electric power network (EPN) substations and a train station. Moreover, the city is crossed longitudinally by a river and the two parts are connected by a series of bridges.

165 buildings of Popoli have been modelled in a shapefile and loaded into QGIS. The map uses the WGS84 coordinated system [24]. Figure 11 shows the hazard map of a hypotetical earthquake scenario, with the earthquake epicentre in the coordinates $(13.47 ; 42.37)$. In this example, local soil effects are neglected. With the support of the tool, it has been possible to immediately visualize the effects on the city.

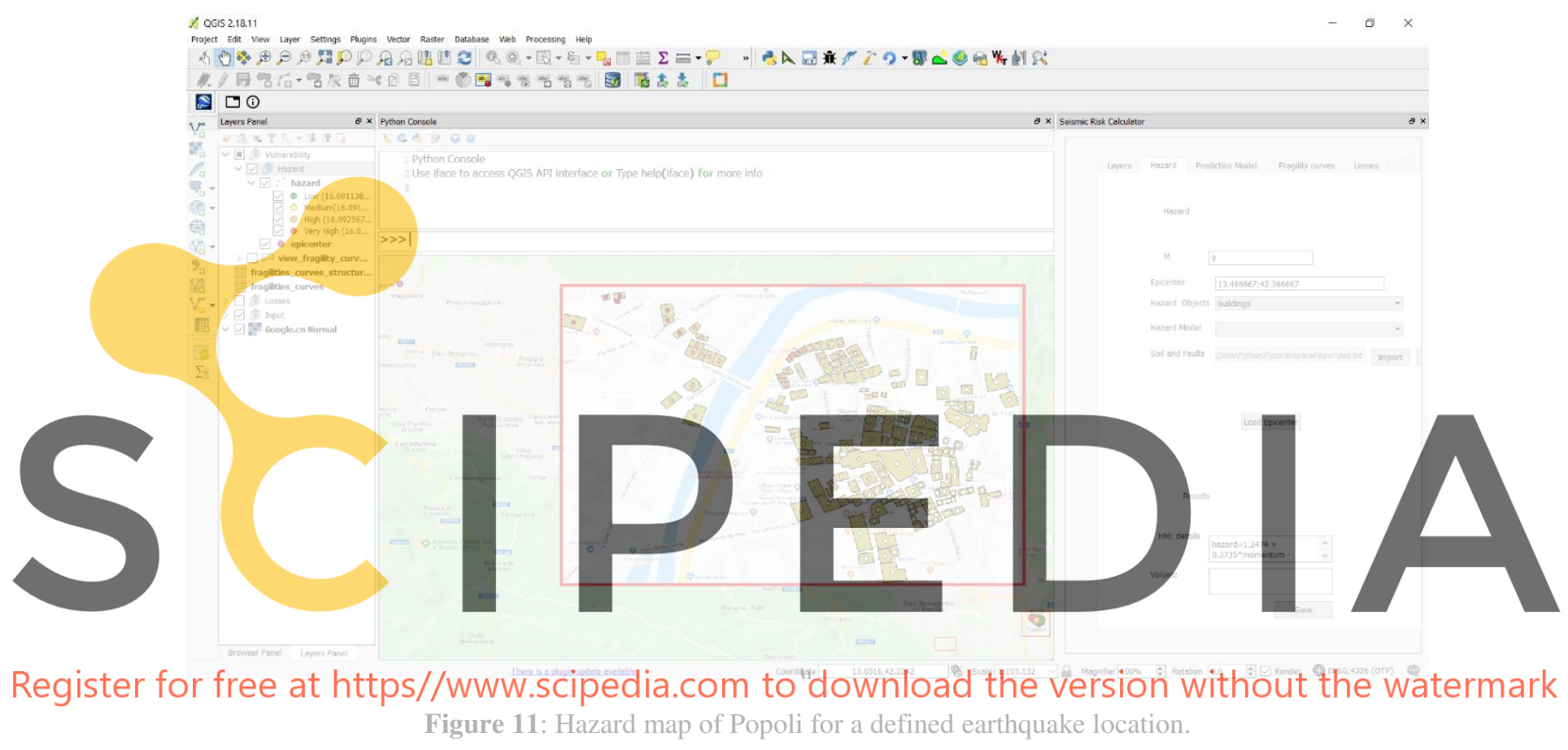

Vulnerability parameters, for the masonry buildings of the historic center, and the fragilities curves, for the other buildings, have been loaded, producing the damage scenarios shown in Figure 12. The colored map clearly identifies the most affected buildings.

The loss estimation is shown in Figure 13 and Figure 14. The total number of casualties and injured as well as the sum of direct economic losses is displayed and, like the damage scenario, a colour map is used to clearly identify the most affected buildings.

\section{CONCLUSIONS}

In this paper, a semi-automated tool to produce seismic risk maps has been presented. This tool includes risk evaluation routines into a GIS platform and it is able to calculate the expected damage or losses, given that information on vulnerability and hazard are provided. The adopted GIS platform is open source. Therefore it can be used by communities free of charge. Future studies will aim to apply this tool to additional case studies in order to improve the method and help cities to achieve a better knowledge of their seismic risk. The proposed tool is a combined effort between civil engineers and computer scientist. 


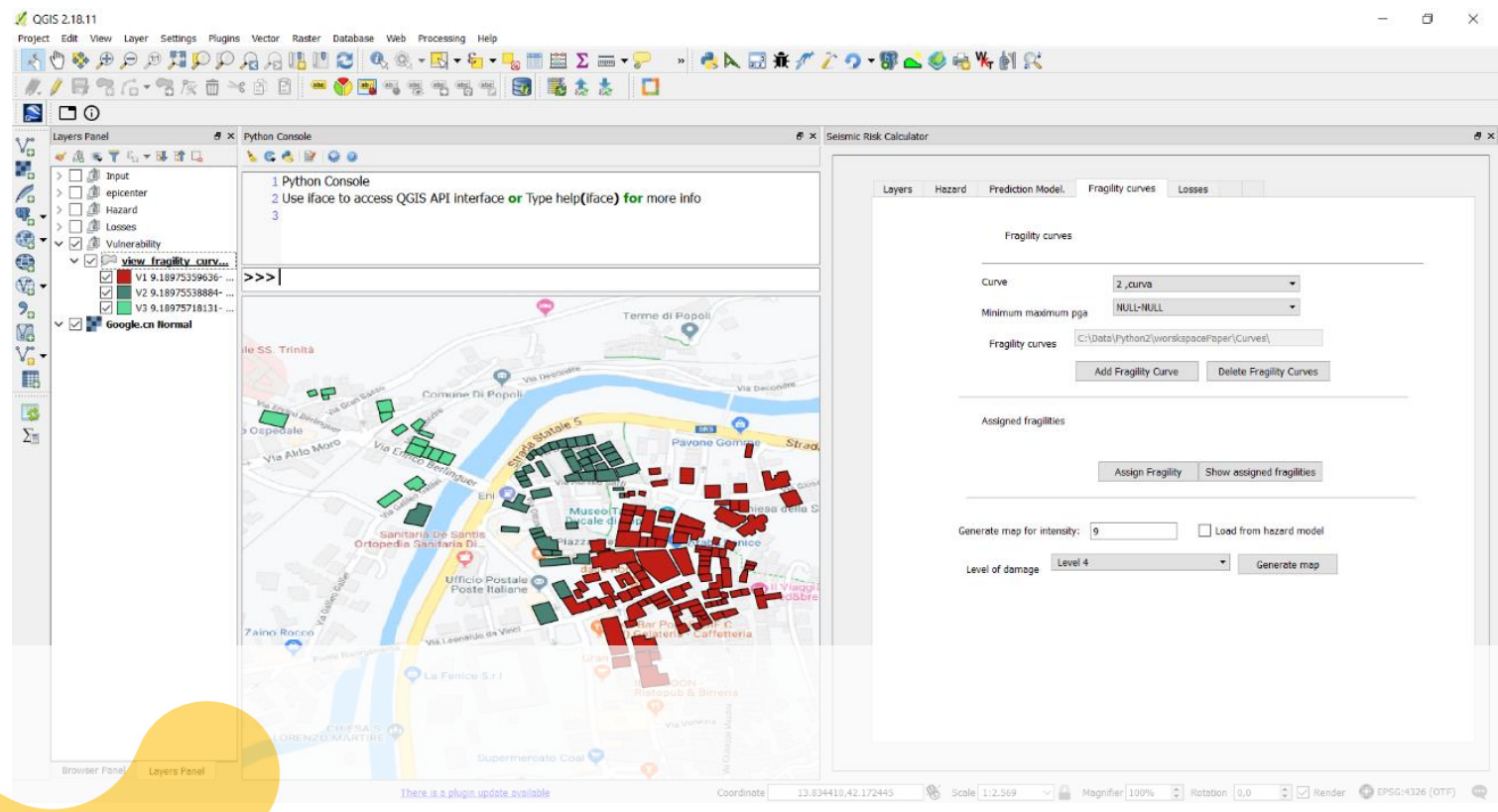

Figure 12. Damage scenarios of Popoli for a hypothetical earthquake location.
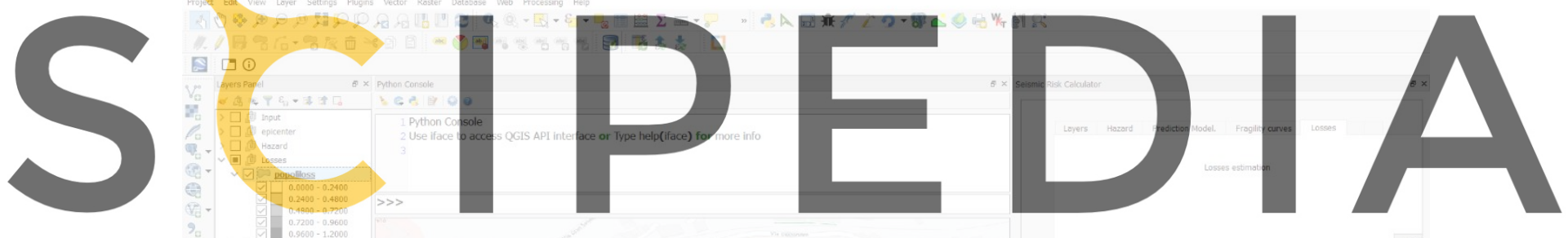

Register for free at https//www.scipedia.com to download the version without the watermark

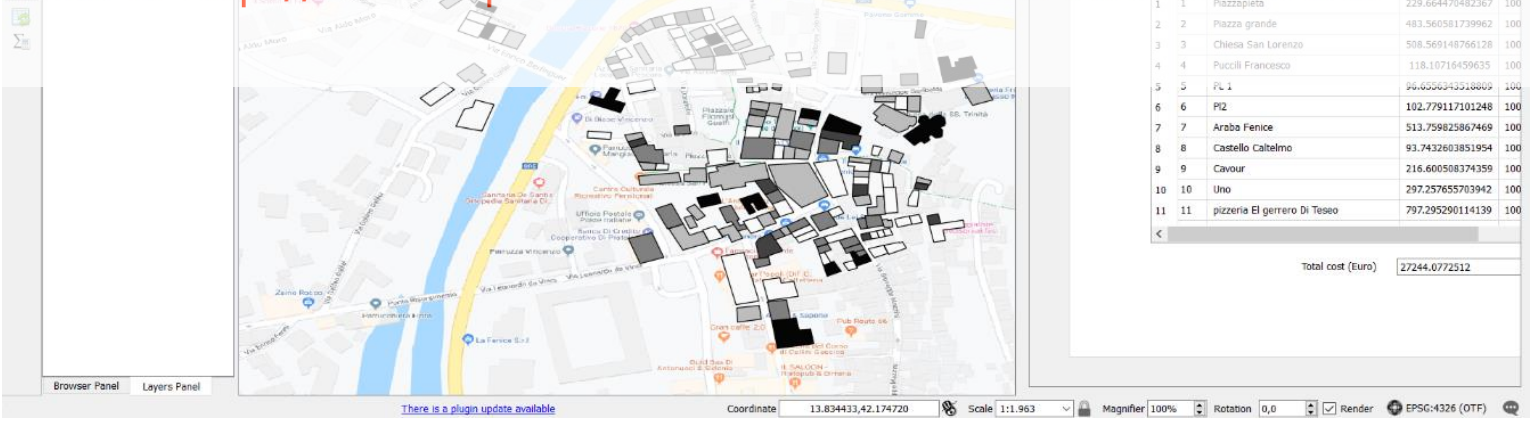

Figure 13: Casualty estimation of Popoli for a defined earthquake location.

Additional developments or inclusion of routines will need not only a proper knowledge of seismic risk but also the technical expertise to implement the desired functionalities. For this reason, it is important to continuously encourage the bridging and cooperation between the two areas of research. 


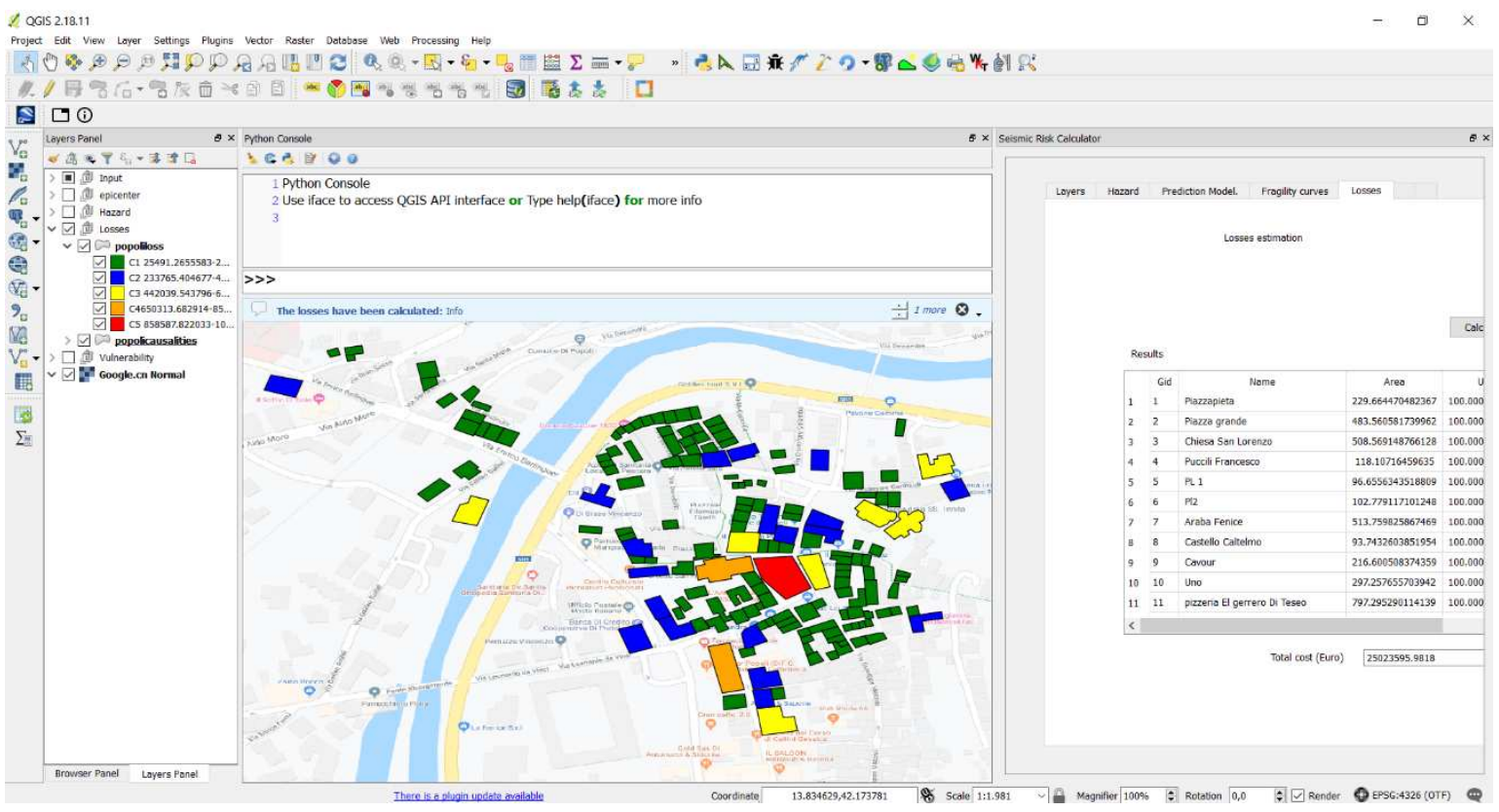

Figure 14. Economic loss estimation of Popoli for a defined earthquake location.

\section{REFERENCES}

[1] Bommer, J.J., Crowley, H., and Pinho, R. A risk-mitigation approach to the management of induced seismicity, Journal of Seismology (2015) 19: 623-646.

[2] Environmental Hazards Methodologies for Risk Assessment and Management (2017) Dalezios N.R. (Ed.) IWA Publishing.

[3] Rapone, D., Brando, G., Spacone, E. and De Matteis G. Seismic vulnerability assessment of historic centers: description of a predictive method and application to the case study of scanno (Abruzzi, Italy) International Journal of Architectural Heritage (2018) 12: 11711195.

[4] Basaglia A., Aprile, A., Spacone, E. and Pilla, F. Performance-based Seismic Risk Assessment of Urban Systems. International Journal of Architectural Heritage (2018) 12 : 1131-1149.

[5] De Matteis, G., Brando, G. and Corlito, V. Predictive model the seismic vulnerability assessment of churches based on the 2009 L'Aquila earthquake. Bulletin of Earthquake Engineering (2019) 17: 4909-4936.

[6] Brando, G., De Matteis, G. and Spacone, E. Predictive model for the seismic vulnerability assessment of small historic centres: Application to the inner Abruzzi Region in Italy. Engineering Structures (2017) 153: 81-96.

[7] Sandi, H., Floricel, I. Analysis of seismic risk affecting the existing building stock. In: Proceedings of the 10th European conference on earthquake engineering (1994) Vienna, 2, pp. 1105-1110.

[8] Grünthal, G. European Macroseismic Scale 1998. Cahiers du Centre Europeen de Geodynamique et de Seismologie (1998) 15: 1-99. 
[9] Porter, K. Beginner's guide to fragility, vulnerability, and risk. Encyclopedia of earthquake engineering (2015): 235-260.

[10] Pitilakis, K., Crowley, H., and Kaynia, A.M. (Eds) SYNER-G: Typology definition and fragility functions for physical elements at seismic risk: buildings, lifelines, transportation networks and critical facilities. Springer Science and Business Media (2014) 27

[11] Federal Emergency Management Agency (2003) Hazus®-MH 2.1Technical Manual. Available at: https://www.fema.gov/media-library/assets/documents/24609.

[12] Longley P. Geographic information systems and science $4^{\text {th }}$ edition. (2015) John Wiley \& Sons.

[13] Bindi, D., Pacor, F., Luzi, L., Puglia, R., Massa, M., Ameri G. and Paolucci R. Ground motion prediction equations derived from the Italian strong motion database. Bulletin of Earthquake Engineering, 9(6): 1899-1920.

[14] Chopra S., Choudhury P. A study of response spectra for different geological conditions in Gujarat, India. Soil Dynamics and Earthquake Engineering,(2011) 31(11):1551-1564, DOI: 10.1016/j.soildyn.2011.06.+007

[15] Kircher, C. A., Reitherman, R. K., Whitman, R. V. and Arnold, C. Estimation of earthquake losses to buildings. Earthquake spectra (1997) 13: 703-720.

[16] Dolce, M. and Manfredi, G. Libro bianco sulla ricostruzione privata fuori dai centri storici nei comuni colpiti dal sisma dell'Abruzzo del 6 aprile 2009. Doppiavoce Edizioni (2015). Italian.

[17] Di Ludovico, M., Prota, A., Moroni, C., Manfredi, G., and Dolce, M. Reconstruction process of damaged residential buildings outside historical centres after the L'Aquila earthquake: part I- "light damage" reconstruction. Bulletin of Earthquake Engineering (2017) 15: 667-692.

[18] Di Ludovico, M., Prota, A., Moroni, C., Manfredi, G., and Dolce, M. Reconstruction process of damaged residential buildings outside historical centres after the L'Aquila earthquake: part II- "heavy damage" reconstruction. Bulletin of Earthquake Engineering (2017) 15: 693-729.

[19] De Martino, G., Di Ludovico, M., Prota, A., Moroni, C., Manfredi, G. and Dolce M. Estimation of repair costs for RC and masonry residential buildings based on damage data collected by post-earthquake visual inspection. Bulletin of Earthquake Engineering (2017) 15: 1681-1706.

[20] Zuccaro, G. and Cacace, F. Seismic casualty evaluation: The Italian model, an application to the L'Aquila 2009 event. In: R. Spence et al. (Eds): Human casualties in earthquakes, Springer, Dordrecht (2011), pp. 171-184.

[21] Chiarabba, C., Amato, A., Anselmi, M., et al. The 2009 L'Aquila (central Italy) MW6. 3 earthquake: Main shock and aftershocks. Geophysical Research Letters (2009) 36:L18308.

[22] Livio, F.A., Michetti, A.M, Vittori E., et al. (2016) Surface faulting during the August 24, 2016, Central Italy earthquake (Mw 6.0): preliminary results. Annals of geophysics (2016) 59(5).

[23] Smith, R.W. (1987). Department of Defense World Geodetic System 1984: its definition and relationships with local geodetic systems. Defense Mapping Agency. 